\title{
HUMOR DALAM MADIHIN JOHN TRALALA DAN HENDRA (KAJIAN JENIS HUMOR PERSPEKTIF VEATCH, GRUNER, DAN HOBBES)
}

\author{
M. Rafiek \\ Universitas Lambung Mangkurat
}

\begin{abstract}
This study aims to describe and explain the types of humor in Madihin John Tralala and Hendra from Veatch, Gruner, and Hobbes perspectives. The method used in this research is descriptive qualitative with content analysis technique. The results of this study are (1) Tight answers humor based on the emotional transformation theory of Veatch, (2) Praise and jokes humor based on Hobbes' theory of excellence, (3) Defense, clarification, not to be outdone humor based on the theory of aggression from Gruner, (4) ) Narrative, association, and contradictory conditions humor according to the emotional transformation theory of Veatch, (5) Rhetorical questions humor based on aggression theory of Gruner, and (6) Association humor according to emotional transformation theory of Veatch.
\end{abstract}

Keywords: type of humor, humor theory of excellence, humor theory of aggression, humor theory of emotional transformation

\begin{abstract}
Abstrak: Penelitian ini bertujuan untuk mendeskripsikan dan menjelaskan jenis humor dalam madihin John Tralala dan Hendra perspektif Veatch, Gruner, dan Hobbes. Metode yang digunakan dalam penelitian ini adalah metode deskriptif kualitatif dengan teknik analisis isi. Hasil penelitian ini adalah ditemukannya (1) Humor Jawaban Ketus berdasarkan Teori Transformasi Emosional dari Veatch, (2) Humor Pujian dan Gurauan berdasarkan Teori Keunggulan dari Hobbes, (3) Humor Pembelaan, Klarifikasi, Tidak Mau Kalah berdasarkan Teori Agresi dari Gruner, (4) Humor Naratif atau Gurauan, Humor Asosiasi, dan Kondisi Kontradiktif menurut Teori Transformasi Emosional dari Veatch, (5) Humor Pertanyaan Retoris berdasarkan Teori Agresi dari Gruner, dan (6) Humor Asosiasi menurut Teori Transformasi Emosional dari Veatch.
\end{abstract}

Kata Kunci: jenis humor, teori humor keunggulan, teori humor agresi, teori humor transformasi emosional

Humor adalah sesuatu yang menggelikan atau membuat orang lain yang menyimak dan menyaksikan tertawa. Sesuatu yang lucu dan menghibur juga dapat dikategorikan sebagai humor. Humor dapat berupa ucapan dan perbuatan dalam kesehariannya. Humor yang baik tentu saja humor yang mendidik dan memberikan sesuatu nilai kepada penyimak dan penontonnya. 
Dikaitkan dengan madihin, humor tentu saja terdapat dalam syair dan pantun madihin. Syair dan pantun madihin yang baik selain memuat unsur-unsur pendidikan di dalamnya juga berisi humor-humor segar yang menggelitik penikmatnya. Di Kalimantan Selatan, ada pamadihinan yang terkenal, yaitu John Tralala dan Hendra. Kedua pamadihinan ini sudah sejak lama dikenal sebagai pamadihinan kocak.

Kedua pamadihinan ini mampu memperlihatkan kepiawaiannya dalam melagukan syair dan pantun madihin, serta menepuk terbang. Terbang adalah sejenis rebana sebagai alat pengiring syair dan pantun yang dilagukan. Seorang pamadihinan harus bisa membawakan madihin sambil menepuk terbang. Kedua keterampilan harus dikuasai oleh pamadihinan. Keterampilan membawakan syair dan pantun madihin secara spontan harus dikuasai dengan baik oleh pamadihinan.

Menurut Jarkasi (2004:2), madihin adalah salah satu bentuk nyanyian rakyat yang berisi nasihat, kritik, sindiran, dan umpatan (pergunjingan) yang dikelola dalam tuturan pepantunan. Namun definisi dari Jarkasi tersebut tidak menyebut alat pengiring madihin, yaitu terbang. Terbang adalah alat tepuk sejenis rebana. Penamaan madihin menurut Bakhtiar Sanderta berasal dari kata madah dan kata akhiran in yang sering diucapkan pamadihinan dengan Ilahiin (Kawi, Jarkasi, Kusasi, 1994: 17). Rafiek (2007: 75) menyatakan bahwa madihin adalah penyajian syair dan pantun dengan dilagukan dan diiringi tepukan tarbang. Madihin ada yang disajikan secara perorangan atau ada pula yang disajikan secara berpasangan. Rafiek (2007:75-78) menyampaikan bahwa struktur penyajian madihin terdiri atas empat, yaitu pendahuluan, pembukaan dan memasang tabi, penyampaian isi (menguran), dan penutup.

Madihin berasal dari kata madah atau syair. Hal itu karena dalam penyajian madihin, pamadihinan selalu melagukan syair. Dalam perkembangannya, pamadihinan juga menggunakan pantun dalam madihinnya. Oleh karena itu, sekarang jika digelar pementasan madihin, pamadihinan akan melagukan syair dan pantun. Hal ini diperkuat dengan pandangan Seman (2010: 5) yang menyatakan bahwa nama madihin diperkirakan berasal dari kata madah. Menurut Kawi, Jarkasi, dan Kusasi (1994: 19), madihin yang dibawakan oleh pamadihinan John Tralala dan Hendra merupakan madihin pop. Rafiek (2012b: 109) menyatakan bahwa syair madihin hampir sama dengan syair Melayu bedanya hanya pada jumlah larik (baris) yang digunakan. Kalau larik syair Melayu terdiri atas empat larik, larik syair madihin bisa kurang dari atau lebih dari empat larik. Rafiek (2012b: 109-111) sepakat dengan Thaha dan Sanderta bahwa struktur penyajian madihin terdiri atas pembukaan, memasang tabi, menyampaikan isi (menguran), dan penutup. Rafiek (2012b: 111) menekankan bahwa keterampilan pamadihinan (ahli madihin) meliputi keterampilan menyampaikan syair secara lisan dan spontan, keterampilan melagukan syair madihin, dan keterampilan menepuk tarbang (sejenis rebana khas untuk madihin).

Rafiek (2013: 190-193) menyatakan bahwa pamadihinan John Tralala dan Hendra menggunakan strategi campur kode dalam madihin-nya. Hal ini menunjukkan bahwa peran bahasa Banjar sebagai penyampai informasi dan hiburan masih diperlukan dalam madihin. Humor akan cepat dipahami oleh para penonton jika dibawakan dalam bahasa Banjar bila penontonnya mayoritas suku Banjar. Sebaliknya, bila penontonnya suku luar Banjar, pamadihinan John Tralala akan beralih kode ke bahasa Indonesia. Hal ini agar penonton dari suku luar Banjar dapat mengerti pesan dan nasihat serta humor yang dibawakan pamadihinan John Tralala dan Hendra.

Rafiek (2012) menemukan 11 jenis humor dalam madihin yang dibawakan pamadihinan John Tralala dan Hendra di Sungai Buluh, yaitu (1) humor bahasa, (2) humor 
pornografi, (3) humor perumpamaan, (4) humor kepolosan atau keterusterangan, (5) humor pengakuan atau kepedean, (6) humor ketegasan atau kenekatan atau keberanian, (7) humor sengaja menyalahkan jawaban, (8) humor kenyataan hidup, (9) humor pengakuan karena malu, (10) humor gurauan, dan (11) humor menyuruh memilih, tetapi sebenarnya ingin mengolok-olok. Rafiek (2014) meneliti bahasa humor dalam syair atau pantun madihin. Bahasa humor yang ada dalam syair atau pantun madihin merupakan diksi yang bisa menimbulkan humor bila dibawakan oleh pamadihinan.

Thaha dan Sanderta (2000: 23) menyatakan bahwa isi syair atau pantun yang dinyanyikan dalam madihin sarat dengan nasihat-nasihat yang bermanfaat dan diselingi dengan humor yang segar. Hal ini menunjukkan bahwa dalam syair atau pantun madihin terdapat humor yang dapat menghibur penonton bila dibawakan oleh pamadihinan. Sekalipun hanya sekadar selingan, humor dalam syair atau pantun madihin menjadi semacam magnet atau daya tarik bagi penonton untuk menyaksikan dari awal sampai akhir pementasan.

Rahmanadji (2007: 217) menjelaskan tentang jenis humor dari Setiawan yang terdiri atas humor personal, humor dalam pergaulan, dan humor dalam kesenian. Rahmanadji (2007: 218) menjabarkan pula tentang humor dalam kesenian yang terbagi atas humor lakuan, humor grafis, dan humor literatur. Rahmanadji (2007: 218) menjelaskan pula teori humor dari Pramono. Pramono (Rahmanadji, 2007: 218) membagi humor menurut penampilannya terdiri atas humor lisan, humor tulisan/gambar, dan humor gerakan tubuh. Pramono (Rahmanadji, 2007: 218) juga membagi humor menurut tujuan dibuatnya atau tujuan pesannya terdiri atas humor kritik, humor meringankan beban pesan, dan humor semata-mata pesan. Sukerti dan Basthomi (2016: 191) menggunakan teori humor berbasis teks dalam menganalisis strategi yang mungkin digunakan oleh penerjemah dalam mempertahankan humor dalam dialog yang ada pada teks terjemahan. Sukerti dan Basthomi (2016: 192-203) menemukan ada humor yang dibatasi secara linguistik, humor yang dibatasi secara budaya, dan humor universal.

Kotthoff (2007: 266-268) menjelaskan tentang melebihi standar dari lelucon yang distandarisasi. Kotthoff (2007: 269-271) menjelaskan tentang efek-efek lucu dari perlambangan-perlambangan dan penyesuaian mode-mode sosial. Kotthoff (2007: 271) menjelaskan tentang meta-jokes. Kotthoff (2007:271-275) menjelaskan tentang stabilisasi dan variabilisasi dalam ejekan atau olok-olok. Kotthoff (2007: 275-278) menjelaskan tentang cerita-cerita humor mengenai masalah-masalah. Kotthoff (2007: 278-283) menjelaskan tentang bersama memfantasikan. Kotthoff (2007: 283-291) menjelaskan tentang bermain dengan norma-norma genre yang terbagi atas humor konseling nutrisional dan gosip humor. Berdasarkan hasil penelitian Kotthoff di atas dapat diketahui bahwa humor terdiri atas humor melebihi standar humor, humor perlambangan, humor meta-jokes, humor ejekan atau olok-olok, humor masalah, humor fantasi, humor konseling nutrisional dan gosip humor.

Secara tradisional, teori humor terdiri atas tiga cabang, yaitu (1) teori keanehan atau keganjilan atau ketidakkonsekuenan atau pertentangan atau bisosiasi, (2) teori superioritas atau peremehan atau kritik atau permusuhan, dan (3) teori pembebasan atau pertolongan atau relaksasi (Kirkmann, 2006: 27-28). Selain pandangan tradisional tersebut, teori humor juga dikembangkan dalam disiplin ilmu semantik. Dalam semantik, terdapat teori semantik berbasis naskah tentang humor yang dikemukakan oleh Raskin tahun 1985 (Kirkmann, 2006: 30). Hipotesis utama dari teori semantik berbasis naskah tentang humor adalah teks dapat dikarakterisasi sebagai kelucuan tunggal dalam teks jika teks dan kelucuan 
dikondisikan memuaskan. Selain teori Raskin tersebut, terdapat pula teori verbal humor dari Raskin dan Attardo tahun 1991 (Kirkmann, 2006: 36). Dalam teori mereka itu, disebutkan bahwa enam level hierarki sumber pengetahuan model representasi kelucuan verbal, yaitu bahasa, strategi naratif, target, situasi, mekanisme logis, dan oposisi naskah (Krikmann, 2006: 37-38).

Bahasa meliputi seтua pilihan tentang level-level fonetik, fonologis, morfofonemik, morfologis, leksik, sintaktik, semantik, dan pragmatik dari struktur bahasa yang penutur masih bebas untuk membuatnya. Strategi naratif bermakna genre atau mikrogenre yang lebih tentang kelucuan, dalam kata-kata lainnya, apakah teks lucu diset sebagai ekspositori, sebagai teka-teki, sebagai urutan pertanyaan dan jawaban, dan lain sebagainya. Target adalah personalisasi objek (individual atau anggota kelompok) tentang kelucuan. Situasi terdiri atas saat istirahat atau santai dari konstituen isi atau "sandaran" dari kelucuan, seperti partisipan lainnya di samping target, aktivitas-aktivitas, objek-objek, instrumentinstrumen, dan lain-lain. Mekanisme logis adalah memahami dalam beberapa pandangan kutipan yang hilang "berpikir rasional dan tindakan" atau "kemungkinan ontologis". Oposisi naskah adalah pertentangan level sangat lemah dalam teori semantik humor berbasis naskah.

Teori humor selanjutnya adalah teori permainan kata dari Attardo tahun 1994. Konstruk teori yang dikembangkan oleh Attardo adalah (1) taksonomi-taksonomi berdasar atas fenomena linguistik seperti homonim, polisemi, antonim, dan lain-lain; (2) taksonomitaksonomi sistematik berdasar atas kategori-kategori linguistik sangat umum, biasanya membedakan antara pengurangan paradigmatik dan sintagmatik atas level lebih atas dari klasifikasi; (3) taksonomi-taksonomi berdasar atas struktur luar yang bertujuan untuk mengukur "jarak fonemik" antara permainan kata; dan (4) taksonomi-taksonomi eklektik. (Kirkmann, 2006: 42).

Veatch (1998: 182) mengemukakan teori humor transformasi emosional. Dalam teori humor transformasi emosional, Veatch menyatakan bahwa humor bisa terjadi disebabkan atau konsekuensi dari transformasi emosional. Veatch (1998: 185) juga memperkenalkan pandangan teoretis tentang kebenaran. teori humor berdasarkan kebenaran dapat menyebabkan humor yang lebih. Gruner (1978) mengemukakan teori humor berdasarkan agresi atau penyerangan. Maksudnya, humor yang dimunculkan berdasarkan serangan dari aggresor kepada orang yang diserang. Oleh karena itu, Veatch (1998: 186) mengemukakan bahwa agresi meliputi interaksi antara aggressor (penyerang) dan aggressee (orang yang diserang). Teori keunggulan dari Thomas Hobbes (Veatch, 1998: 187). Dalam teori humor berdasarkan keunggulan dijelaskan adanya peranan perasaan keunggulan dalam humor. Berdasarkan teori-teori humor yang disajikan di atas, peneliti menggunakan teori humor berdasarkan transformasi emosional dari Veatch, teori humor berdasarkan agresi dari Gruner, dan teori humor berdasarkan keunggulan dari Hobbes. Tiga teori humor ini digunakan untuk menemukan jenis dan makna humor dalam madihin John Tralala dan Hendra.

Teori humor Veatch dikenal juga dengan teori pelanggaran (Mulder and Nijholt, 2002: 5). Teori pelanggaran Veatch mensyaratkan tiga kondisi, yaitu (1) pelanggaran terhadap komitmen tertentu, (2) orang yang merasa telah mendominasi perasaannya dalam situasi tertentu adalah normal, dan (3) kejadian pada waktu yang bersamaan (Mulder and Nijholt, 2002:5-6). Oleh karena itu, Veatch (Mulder and Nijholt, 2002: 6) menyatakan bahwa humor adalah gambaran emosional yang tidak menyakiti. 
Humor dihasilkan dari suatu perasaan yang tak diduga-duga dari keberhasilan, memberi kesan peremehan adalah lucu ketika humor menjadikan korban orang lain atau diri di masa lalu (Gruner, 1997; Hobbes, 1651/1968). Humor Gruner dan Hobbes adalah humor yang memberikan kesan peremehan tetapi dianggap lucu.

\section{METODE PENELITIAN}

Metode yang digunakan dalam penelitian adalah metode penelitian deskriptif kualitatif. Teknik analisis yang digunakan dalam penelitian ini adalah teknik analisis isi. Teknik analisis isi digunakan untuk membuat inferensi-inferensi yang dapat direfleksikan dan sahih data dengan memperhatikan konteksnya (Krippendorff, 1991: 15). Analisis isi harus dilaksanakan berkaitan dan dijustifikasi dalam hubungannya dengan konteks data (Krippendorff, 1991: 19). Penggunaan analisis isi dalam penelitian ini sangat sesuai dengan komentar Krippendorff (1991: 23) yang menyatakan bahwa sebuah analisis isi, walaupun untuk tujuan deskriptif, tidak boleh kebal terhadap pertimbangan-pertimbangan kesahihan dan konteks yang disinggung oleh temuan-temuannya harus spesifik.

Sumber data penelitian ini adalah video rekaman madihin John Tralala dan Hendra pada saat penutupan pagelaran seni budaya yang diadakan tanggal 18 November 2012. Data penelitian ini adalah semua syair dan pantun madihin yang dibawakan oleh John Tralala dan Hendra. Data ditranskripsikan dari sumber data dengan cara menonton dan menyimak secara berulang-ulang video madihin John Tralala. Setelah itu, data yang sudah ditranskripsikan dianalisis dengan menggunakan teknik analisis isi. Hasil temuan yang diperoleh kemudian dibahas dengan menggunakan teori humor dari Veatch, Gruner, dan Hobbes. Menurut Ratna (2015: 49), teknik analisis isi menekankan bagaimana makna isi komunikasi. Dalam hal ini adalah makna isi syair madihin John Tralala dan Hendra. Oleh karena itu, menurut Endraswara (2006: 162), prosedur analisis isi harus memenuhi persyaratan seperti (1) teks sastra perlu diproses secara sistematis, menggunakan teori yang telah dirancang sebelumnya, (2) teks tersebut dicari unit-unit analisis dan dikategorikan sesuai acuan teori, (3) proses analisis harus mampu menyumbangkan ke pemahaman teori, (4) proses analisis mendasarkan pada deskripsi, dan (5) analisis dilakukan secara kualitatif.

\section{HASIL DAN PEMBAHASAN}

\section{Jenis dan Makna Humor dalam Madihin John Tralala dan Hendra Perspektif Veatch,} Gruner, dan Hobbes

\section{Humor Jawaban Ketus berdasarkan Teori Transformasi Emosional dari Veatch}

Dalam struktur penyajiannya, madihin terdiri atas pembukaan dan mengucapkan salam, memasang tabi, penyampaian isi atau menguran, dan penutup.

Pembukaan dan Mengucapkan Salam

Hendra $\quad$ Ilahiii...kalau...kalaulah kalaulah kita... awan ...awan...kalau...awan
Kalau lah kita menjadi ... awan...awan...
Jhon Tralala : Assamu'alaikum ini saya sampaikan
Hendra $\quad$ :Wa'alaikumsalam saya beri jawaban


Dalam pembukaan dan mengucap salam di atas terlihat tidak terdapat humor. Hal itu karena dalam pembukaan dan mengucapkan salam hanya merupakan pembuka dan memberi salam kepada para penonton atau hadirin. Sekalipun begitu memang ada upaya Hendra untuk membuat efek lucu dengan langsung memberi jawaban atas salam dari ayahnya. Jawaban Hendra tersebut dilakukan dengan cepat agar memberikan irama yang sahut-menyahut.

Memasang Tabi

Jhon Tralala: Salam sejahtera untuk kita sekalian

Hari ini gembira perasaan

pagelaran seni yang lagi kita saksikan

Fakultas Ekonomi yang menyelenggarakan

Generasi muda harus cinta kesenian

tongkat estafet seniman perlu kitalah teruskan

agar seni kita di Kalimantan Selatan

jangan sampai punah jangan sampai hilang

ayo kita bekerja mari bertepuk tangan

Dalam memasang tabi di atas, John Tralala belum memunculkan humor dalam madihin-nya. Yang ada hanyalah pengucapan salam sejahtera dan perasaan gembira atas pergelaran seni yang diadalah Fakultas Ekonomi Universitas Lambung Mangkurat. John Tralala juga mengingatkan dalam madihinnya agar generasi muda harus mencintai kesenian agar jangan sampai punah. Akan tetapi, di akhir madihin-nya, John Tralala mengajak hadirin untuk bertepuk tangan. Hal ini membuat ramai suasana.

Penyampaian Isi (Manguran)

Hendra: Memang benar itu demikian

pada hari ini seperti kita saksikan

dalam acara pergelaran

Seni dan budaya Kalimantan Selatan

Fakultas Ekonomi Lambung Mangkurat yang meadakan

ada lagi Badan Eksekutif Mahasiswanya ini yang merencanakan

sukses sekali ini dilaksanakan

bermacam lomba ini diadakan

dari baturai pantun (dari bertanding pantun)

bakisah bahasa Banjar (bercerita bahasa Banjar)

sampai lomba mamanda ini diadakan

ini merupakan apresiasi seni yang sangat mengagumkan

Generasi muda kita semua ini harus berjuang

agar nanti seni budaya Kalimantan Selatan

jangan sampai hilang

dari sekarang sampai nanti itu tetap dikenang 
Dalam penyampaian isi madihin yang disampaikan oleh Hendra di atas tidak terdapat humor. Yang ada hanyalah informasi tentang acara pergelaran seni budaya Kalimantan Selatan oleh Badan Eksekutif Mahasiswa, Fakultas Ekonomi Universitas Lambung Mangkurat yang sukses. Selain itu, Hendra juga menyampaikan tentang lomba-lomba yang diadakan seperti baturai pantun atau berbalas pantun, bakisah atau bercerita bahasa Banjar dan lomba mamanda atau teater rakyat. Di akhir madihin-nya, Hendra mengingatkan agar generasi muda melestarikan seni budaya Kalimantan Selatan.

John Tralala: Memang benar anak yang kucintai

Kita semua para generasi

harus cinta seni

kalau diri kita punya seni

kalau nanti jadi pegawai negeri

minimal pejabat tinggi

jadi tentara nak ai jadi polisi

pasti jadi komandan itu sudah pasti

Dalam penyampaian isi yang disampaikan oleh John Tralala di atas masih mengingatkan agar generasi muda mencintai seni meskipun nantinya sudah bekerja seperti menjadi pegawai negeri, pejabat tinggi, tentara, polisi, dan komandan.

Hendra : Kalau seumpama saya tinggal di kampung

John Tralala : Minimal jadi RT

Hendra : Walau jadi RT saya juga senang hati

tapi dengan seni saya senang sekali

kalau jadi RT seumpama

Masyarakat yang bikin KTP

langsung saya layani

John Tralala : Seumpama pang nanti aku nang bikin? (Seumpama nanti aku yang buat?)

Hendra : Jelas tidak kuberi

John Tralala : Apa alasannya ikam kada membari? (Apa alasannya kamu tidak memberi?)

Hendra $\quad$ : Bisa salah gunakan dibawanya babini (Bisa salah gunakan dibawanya beristri)

Dalam penyampaian isi di atas dapat diketahui bahwa Hendra dan John Tralala saling bertanya jawab melalui madihin mereka. Hendra lebih dahulu menanyakan kepada ayahnya "kalau seumpama saya tinggal di kampong". Lalu John Tralala menjawab pertanyaan anaknya dengan sahutan "Minimal jadi RT (Rukun Tetangga)". Namun Hendra tetap bangga dengan mengatakan "Walau jadi RT, saya juga senang hati, tapi dengan seni saya senang sekali, kalau jadi RT, seumpama masyarakat yang bikin KTP, langsung saya layani". Kemudian John Tralala bertanya lagi kepada anaknya "Seumpama pang nanti aku nang bikin? (seumpama nanti aku yang buat?)". Hendra dengan tegas menjawab dalam madihin-nya, "Jelas tidak kuberi". John Tralala bertanya lagi "Apa alasannya ikam kada membari? (apa alasannya kamu tidak memberi?)". Hendra langsung menjawab "Bisa salah gunakan dibawanya babini (Bisa disalahgunakan, dibawanya beristri)". Jawaban Hendra ini dalam madihin-nya tentu saja membuat penonton yang menyaksikan dan mendengarnya 
tertawa. Permainan kata dalam madihin Hendra diwujudkan dengan humor jawaban ketus berupa bisa salah gunakan dibawanya babini (Bisa disalahgunakan, dibawanya beristri).

\section{Humor Pujian dan Gurauan berdasarkan Teori Keunggulan dari Hobbes}

John Tralala: Babini... aaa aw...awan (Beristri ... aaa aw...awan)

$$
\begin{aligned}
& \text { Bapak ibu undangan yang tercinta } \\
& \text { malam ini sungguh luar biasa } \\
& \text { coba penonton banyak mahasiswa } \\
& \text { padahal anak saya Hendra ganteng orangnya } \\
& \text { tetapi tuh di muka itu mirip Ridho Rhoma } \\
& \text { John Tralala lestari penampilannya } \\
& \text { mirip Jackie Chan bintang Hongkong China }
\end{aligned}
$$

Dalam kutipan madihin di atas dapat diketahui bahwa pamadihinan John Tralala melakukan humor pujian. Humor pujian yang dimaksud adalah ketika pamadihinan John Tralala memuji anaknya Hendra yang ganteng dan mirip Ridho Rhoma. Pamadihinan John Tralala pun memuji dirinya sendiri dengan mengatakan mirip Jackie Chan bintang Hongkong Cina. Humor pujian ini dilakukan oleh pamadihinan John Tralala untuk membuat hadirin tersenyum bahkan tertawa.

Hendra: Oh, para penonton malam ini jadi tersenyum

karena bapak dengan diri menyanjung

coba anda lihat berdiri para penonton

Bapak John Tralala memang ganteng

seperti artis sinetron

tapi bukan seperti bintang film Hongkong

tapi bintang film Jepang mirip banar Doraemon (tapi bintang film Jepang mirip sekali Doraemon)

Sebaliknya, pamadihinan Hendra melakukan humor gurauan yang dalam bahasa Banjar humor maambung dahulu hanyar mahantak (menyanjung dahulu baru dihentak) atau humor hapakan atau mahapak atau manyambati (mengata-ngatai). Hal ini terlihat dari cara Hendra menyampaikan madihinnya dengan mengatakan "Karena bapak dengan diri menyanjung, coba anda lihat berdiri para penonton, bapak John Tralala memang ganteng seperti artis sinetron, tapi bukan seperti bintang film Hongkong, tapi bintang film Jepang mirip banar (sekali). Doraemon." Madihin Hendra ini tentu saja akan membuat penonton tertawa karena ia mengatakan dalam madihin-nya bahwa ayahnya mirip sekali Doraemon.

\section{Humor Pembelaan, Klarifikasi, Tidak Mau Kalah berdasarkan Teori Agresi dari Gruner}

John Tralala: Doraemon.... aduh Hendra anakku tercinta

jangan begitu bapandir di mahasiswa (jangan begitu bicara di mahasiswa)

Aku jadi supan, jadi malu jadinya (Aku jadi malu, jadi malu jadinya)

semestinya Hendra kamu menyadarinya

kalau bukan aku yang mirip Doraemon 
Ikam pasti nak ai kada lahir ke dunia (Kamu pasti nak ai tidak lahir ke dunia)

Dalam madihin yang dibawakan oleh pamadihinan John Tralala di atas terdapat humor pembelaan. Dalam humor pembelaan yang dibawakan pamadihinan John Tralala terdapat pembelaannya sekalipun dikatakan kalau bukan aku yang mirip Doraemon, ikam pasti nak ai kada lahir ke dunia. Upaya humor pembelaan yang dilakukan oleh pamadihinan John Tralala tentu akan membuat hadirin tertawa karena dibawakan dengan bahasa yang kocak.

Hendra: Wahai yang tercinta bapak John Tralala

Yang melahirkan saya itu bukan bapak

Tapi yang melahirkan ibu saya tercinta

Pamadihinan Hendra pun tidak mau kalah atas madihin yang bawakan ayahnya, ia lalu menyampaikan wahai yang tercinta bapak John Tralala, yang melahirkan saya itu bukan bapak, tapi yang melahirkan ibu saya tercinta. Dalam madihin yang dibawakan Hendra terdapat humor klarifikasi atau humor tidak mau kalah bahwa yang melahirkan memang ibunya bukan ayahnya. Hal ini tentu saja membuat penonton semakin gembira dan tertawa.

John Tralala: Tapi itu hasil kerja sama

antara kami bedua (antara kami berdua)

Walau Ibu kamu yang melahirkannya

tapi aku juga yang jadi sponsornya

sponsornya...aaaw...awan

Si Hendra anak yang kucintai

Orangnya ganteng tapi lamah bulu

kada kawa diganggu cewe (tidak bisa diganggu cewek)

Di Balikpapan ada pang minggu tadi

Kami madihin acara seperti ini

Ada cewe cantik orangnya tinggi

Kaya Tamara Blezensky (Seperti Tamara Blezensky)

Burit bahenol kaya Elvie Sukaisih (Pantat bahenol seperti Elvie Sukaesih)

Senyumnya manis mirip banar Syahrini (Senyumnya manis mirip sekali Syahrini)

Tapi aku tahual setengah mati (Tapi aku bertengkar setengah mati)

Cewenya kesurupan, matanya manciling (Ceweknya kesurupan, matanya melotot)

Liur sampai $k a$ pipi

Ternyata itu cewe menderita gila babi (Ternyata itu cewek menderita ayan)

Humor tidak mau kalah pun dikeluarkan oleh pamadihinan John Tralala untuk menjawab madihin anaknya dengan mengatakan "Tapi itu hasil kerja sama antara kami bedua, walau ibu kamu yang melahirkannya, tapi aku juga yang jadi sponsornya”. Hal ini ia sampaikan agar terlihat tidak kalah di hadapan penonton dalam penyajiannya madihin-nya. 


\section{Humor Naratif atau Gurauan, Humor Asosiasi, dan Kondisi Kontradiktif berdasarkan Teori Transformasi Emosional dari Veatch}

Di dalam madihin John Tralala di atas juga disajikan humor gurauan yang didahului dengan menyanjung anaknya lalu berupaya mengatainya seperti terlihat dalam kutipan si Hendra anak yang kucintai, orangnya ganteng tapi lamah bulu (lemah bulu), kada kawa diganggu cewe (tidak bisa diganggu cewek). Selanjutnya, pamadihinan John Tralala menyampaikan humor naratif tentang seorang cewek yang terkena penyakit ayan. Humor naratif itu dapat dilihat dari kutipan "Di Balikpapan ada pang minggu tadi, kami madihin acara seperti ini, ada cewek cantik orangnya tinggi, kaya Tamara Blezensky, burit bahenol kaya Elvie Sukaesih, senyumnya manis mirip banar Syahrini, tapi aku tahual setengah mati, cewenya kasurupan, matanya manciling, liur sampai ka pipi, ternyata itu cewe menderita gila babi (Di Balikpapan ada minggu tadi, kami madihin acara seperti ini, ada cewek orangnya tinggi, seperti Tamara Blezensky, pantat bahenol seperti Elvie Sukaesih, senyumnya manis mirip sekali Syahrini, tapi aku bertengkar setengah mati, ceweknya kesurupan, matanya melotot, liur sampai ke pipi, ternyata itu cewek menderita ayan)". Humor naratif ini tentu saja membuat hadirin yang menyaksikan tertawa terbahak-bahak. Humor naratif ini dapat pula disebut humor gurauan karena pamadihinan bergurau tentang wanita yang terkena penyakit ayan.

Hendra: Malam ini jua ulun mangisahakan (Malam ini juga saya menceritakan)

$$
\begin{aligned}
& \text { Bapak John Tralala sidin ada pengalaman (Bapak John Tralala beliau ada } \\
& \text { pengalaman) } \\
& \text { waktu sidin ini handak mencari pasangan (Saat beliau ini hendak mencari } \\
& \text { pasangan) } \\
& \text { yang namanya Nurul langsung mancariakan (Yang namanya Nurul langsung } \\
& \text { mencarikan) } \\
& \text { tapi sidin ini orangnya pamilihan (tapi beliau ini orangnya terlalu pilih) } \\
& \text { Dia telalu pilih tadapat babanciran (Dia terlalu pilih dapat bencong) } \\
& \text { nang ngaran bancir pian tahu saurangan (Yang namanya bencong anda tahu } \\
& \text { sendiri) } \\
& \text { waktu sidin ini handak bemesraan (Saat beliau ini hendak bermesraan) } \\
& \text { dibelainya rambut dengan penuh kasih sayang } \\
& \text { lalu bancinya itu merasaakan (lalu bencongnya itu merasakan) } \\
& \text { Bapak John Tralala hahar tarus-tarusan (Bapak John Tralala raba terus-terusan) } \\
& \text { sakalinya hampir takajut tahahar kapala haruan (Sekalinya hampir terkejut teraba } \\
& \text { kepala ikan gabus) }
\end{aligned}
$$

Pamadihinan Hendra juga tidak mau kalah dengan menyampaikan humor naratif juga tentang ayahnya yang bertemu waria. Humor naratif yang disampaikan oleh pamadihinan Hendra adalah tentang kisah pengalaman ayahnya. Adapun humor naratif dapat diketahui dari kutipan "Tapi sidin ini orangnya pamilihan, dia telalu pilih tadapat babanciran (Tapi beliau ini orangnya terlalu pilih, dia terlalu pilih, bertemu waria)". Selain itu, dalam madihin-nya, Hendra menyelipkan juga humor asosiasi yang bisa dilihat dalam kutipan "Bapak John Tralala hahar tarus-tarusan, sakalinya hampir takajut tahahar kapala haruan (Bapak John Tralala raba terus-terusan, sekalinya hampir terkejut teraba kepala ikan 
gabus)". Humor asosiasi dimaksud terkait dengan penyebutan kapala haruan (kepala ikan gabus). Dalam Kamus Besar Bahasa Indonesia Pusat Bahasa (Departemen Pendidikan Nasional, 2008: 94), asosiasi diartikan sebagai tautan dalam ingatan pada orang atau barang lain dan mengasosiasikan berarti menautkan sesuatu pada orang atau barang lain. Penyebutan kepala ikan gabus merupakan asosiasi dari alat kelamin laki-laki.

John Tralala: Haruan...aaawan aw...wan (Ikan gabus...aaawan aw...wan)

Baik madihin malam ini kita teruskan

untuk menghibur tamu para undangan

supaya meriah sekali lagi bertepuk tangan

nyaman haja sampian betapuk tangan (nyaman saja anda (hadirin) bertepuk tangan)

Ulun di atas maka am baliuran (Saya di atas maka berliur)

tangan singkal muntung babuihan (tangan pegal mulut berbuih)

nang jelas banar ini paluh kaluaran (yang jelas sekali ini keringat keluar)

karna kipas angin panitia kada menyediakan (karena kipas angin panitia tidak menyediakan)

mohon maaf ulun hanya bagagayaan (mohon maaf saya hanya main-main)

secara jujur anak yang kucintai

hari ini bangga perasaan

bermacam seniman pentas ditampilkan

dari nang waras handak nang gegilaan (dari yang sehat/sembuh hendak yang gila)

namanya seni kita harus bisa

menerima dengan hati yang senang

apa lagi anakku tersayang

memilih gadis macam apa gerangan?

pilih orang Banjar atau orang Kandangan

orang Jawa ih atau orang Medan

nang putih cari orang Thailand (Taiwan) (Yang putih cari orang Thailand (Taiwan))

kalu nang hirang cari orang Irian (Kalau yang hitam cari orang Irian)

Dalam madihin yang disampaikan oleh pamadihinan John Tralala adalah humor kondisi kontradiktif. Humor kondisi kontradiktif adalah humor yang berisi keadaan penonton yang sangat bertentangan dengan keadaan si pamadihinan. Hal ini bisa dilihat dari kutipan "Nyaman haja sampiyan batapuk tangan, ulun di atas maka am baliuran, tangan singkal muntung babuihan, nang jelas banar ini paluh kaluaran (Nyaman saja hadirin bertepuk tangan, saya di atas sedang berliur, tangan pegal mulut berbuih, yang jelas sekali ini peluh (keringat) keluar)". Kondisi hadirin tentu saja sangat bertolak belakang dengan kondisi si pamadihinan yang kelelahan karena sedari tadi bermain madihin. Tetapi pemilihan kata yang tepat dalam pertunjukan madihinnya membuat penonton tertawa. 
Dalam madihin-nya, pamadihinan John Tralala juga menyampaikan humor gurauan yang di akhiri dengan permohonan maaf, seperti terlihat pada kutipan "Karna kipas angin panitia kada manyadiakan, muhun maaf ulun hanya bagagayaan (Karena kipas angin panitia tidak menyediakan, mohon maaf saya hanya bergurau)".

Hendra: Masalah wanita jangan tapi dipersoalkan

tapi memilih wanita jelas tidak sembarangan

harus yang baik itu juga beriman

harus yang taat itu pun peraturan

berbudi baik juga bersifat sopan

masalah suku tak usah dipersoalkan

baik orang Jawa atau orang Medan

baik orang Sunda atau orang Ujung Pandang

baik orang Jakarta atau orang Kalimantan

Dalam kutipan di atas dapat diketahui pamadihinan Hendra hanya menyampaikan pesan-pesan dalam memilih wanita sebagai pendamping hidup. Hal itu dapat diketahui dari kutipan "Masalah wanita jangan dipersoalkan, tapi memilih wanita jelas tidak sembarangan, harus yang baik itu juga beriman, harus yang taat itu pun peraturan, berbudi baik juga bersifat sopan, masalah suku tak usah dipersoalkan, baik orang Jawa atau orang Medan, baik orang Sunda atau orang Ujung Pandang, baik orang Jakarta atau orang Kalimantan". Hal ini dilakukan oleh Hendra dalam madihin-nya karena yang hadir banyak mahasiswa.

\section{Humor Pertanyaan Retoris berdasarkan Teori Agresi dari Gruner}

John Tralala: Itu sangat bagus asal jangan Uranghutan

tapi Hendra anak yang kucintai

kalau memilih artis nak ai resikonya tinggi

kalau handak jua Bapak carikan malam ini

lawan Luna Maya atawa Cut Tari (dengan Luna Maya atau Cut Tari)

Hendra : Kalau lawan nang ngitu jelas ulun kada wani (Kalau dengan yang itu jelas saya tidak berani)

John Tralala: Apa alasannya Hendra tidak berani?

Hendra : Kenapa mas Ariel bisa ditangkap pulisi? (Mengapa mas Ariel bisa ditangkap polisi?)

Dalam madihin yang disampaikan oleh pamadihinan John Tralala dan Hendra secara berganti sahut-menyahut di atas terdapat humor pertanyaan retoris yang dilakukan oleh Hendra. Hal itu dapat diketahui dari hasil tanya jawab dalam madihin mereka. John Tralala menyampaikan "Kalau memilih artis nak ai resikonya tinggi, kalau handak jua bapak carikan malam ini, lawan Luna Maya atawa Cut Tari (kalau memilih artis nak resikonya tinggi, kalau hendak juga bapak carikan malam ini, dengan Luna Maya atau Cut Tari). Lalu dijawab oleh Hendra, kalau lawan nang ngitu jelas ulun kada wani (Kalau dengan yang itu jelas saya tidak berani)". Jhon Tralala lalu bertanya lagi "Apa alasannya Hendra 
tidak berani?" . Hendra pun menjawab "Kenapa mas Ariel bisa ditangkap pulisi? (Mengapa mas Ariel bisa ditangkap polisi?)". Jawaban Hendra yang berisi pertanyaan retoris yang tidak perlu dijawab karena jawabannya sudah diketahui oleh umum melalui infotainment di televisi. Jawaban Hendra berupa humor pertanyaan retoris itu tentu saja membuat penonton tertawa.

Penutup

John Tralala: Pulisi... Tidak lama nak ai bamadihinan (Polisi ... Tidak lama nak ai bermadihin)

karena penonton menantikan pengumuman

siapa nanti yang akan jadi pemenang

menurut informasi tadi ada laporan

acara dari hari sabtu itu pembukaan

malam ini nak ai kita penutupan

Panitia jaga kesehatan

menjaga kesehatan sama merawatnya

seperti sepeda motor nak ai kendaraan kita

Dalam madihin yang dibawakan oleh pamadihinan John Tralala di atas dapat diketahui hanya berisi pemberitahuan dan nasihat. Pemberitahuannya bahwa madihin yang mereka bawakan sebentar saja karena penonton menunggu pengumuman pemenang lomba. Pamadihinan John Tralala juga memberitahukan bahwa pembukaan kegiatan tersebut dilakukan pada hari Sabtu, sedangkan mereka tampil pada acara penutupan yang dilakukan pada Minggu malam tanggal 18 November 2012. Nasihatnya adalah agar panitia menjaga kesehatan yang disamakannya dengan merawat sepeda motor.

\title{
Humor Asosiasi berdasarkan Teori Transformasi Emosional dari Veatch
}

\author{
Hendra : Kalo sepeda motor itu ada lampunya \\ ada setangnya ada lain sebagainya \\ John Tralala : Coba perhatikan adik-adik manusia \\ dalam tubuh kita ini ada persamaannya \\ Hendra : Kalau begitu saya langsung bertanya \\ Kalau mata kita? \\ John Tralala : Ibarat kendaraan ini adalah lampunya \\ Hendra : Kalau telinga? \\ John Tralala : Jelas itu reetingnya \\ Hendra : Kalau hidung? \\ John Tralala : Ini kelaksonnya \\ Hendra : Kalau mulut? \\ John Tralala : Pengisi bahan bakarnya \\ Hendra : Kalau tangan ?
}


John Tralala : pasti itu setangnya

Hendra : Kalau perut?

John Tralala : Jelas itu tangkinya.

Hendra : Kalau di bawah perut?

John Tralala : Pasti itu businya.

John Tralala : Asalammualaikum wr.wb.

Dalam madihin di atas dapat diketahui bahwa pamadihinan John Tralala dan Hendra menggunakan humor asosiasi. Humor asosiasi yang digunakan oleh pamadihinan Jhon Tralala untuk menjawab pertanyaan pamadihinan Hendra. Humor asosiasi tersebut dilakukan oleh pamadihinan John Tralala dengan mengasosiasikan tubuh manusia dengan sepeda motor. Humor asosiatif itu dapat kita ketahui dari kutipan tanya jawab yang dilakukan pamadihinan Hendra dan John Tralala. Hendra bertanya "Kalau mata kita?" . John Tralala menjawab "Ibarat kendaraan ini adalah lampunya". Hendra bertanya lagi, "Kalau telinga?" "Jelas itu reetingnya", jawab pamadihinan John Tralala. Hendra lalu bertanya, "Kalau hidung?" "Ini kelaksonnya", jawab pamadihinan John Tralala. Hendra kemudian bertanya, "Kalau mulut?" "Pengisi bahan bakarnya", jawab pamadihinan John Tralala. Hendra pun kembali bertanya, "Kalau tangan?" "Pasti itu setangnya", jawab pamadihinan John Tralala. Hendra kembali bertanya "Kalau perut?" "Jelas itu tangkinya" , jawab pamadihinan John Tralala. Hendra pun tetap bertanya, "Kalau di bawah perut?" "Pasti itu businya", jawab pamadihinan John Tralala. Jawaban pamadihinan John Tralala, "Pasti itu businya" tentu saja memancing gelak tawa penonton karena busi mengasosiasikan pada alat kelamin yang ada di bagian bawah perut. Humor asosiasi ini mampu menimbulkan efek lucu yang membuat penonton tertawa.

\section{SIMPULAN DAN SARAN}

\section{Simpulan}

Berdasarkan pembahasan dan analisis di atas dapat disimpulkan bahwa pamadihinan John Tralala dan Hendra menggunakan jenis humor terutama dalam penyampaian isi atau menguran. Jenis humor yang dilakukan oleh pamadihinan John Tralala antara (1) humor pujian, (2) humor pembelaan, (3) humor tidak mau kalah, (4) humor naratif, (5) humor kondisi kontradiktif, dan (6) humor asosiasi. Jenis humor yang dilakukan oleh pamadihinan Hendra adalah (1) humor jawaban ketus, (2) humor gurauan, (3) humor tidak mau kalah, (4) humor naratif, (5) humor asosiasi, dan (6) humor pertanyaan retoris. Jadi, secara keseluruhan humor yang ditemukan dalam madihin John Tralala dan Hendra pada saat pementasan pagelaran seni budaya yang diadakan oleh Badan Eksekutif Mahasiswa, Fakultas Ekonomi Universitas Lambung Mangkurat terdiri atas (1) humor pujian, (2) humor pembelaan, (3) humor tidak mau kalah, (4) humor naratif, (5) humor kondisi kontradiktif, (6) humor asosiasi, (7) humor jawaban ketus, (8) humor gurauan, dan (9) humor pertanyaan retoris.

\section{Saran}

Kepada peneliti selanjutnya disarankan agar melakukan penelitian teks madihin John Tralala dan Hendra dengan teori humor Raskin (1985). Selain itu, peneliti selanjutnya 
disarankan untuk melakukan kajian humor dengan menggunakan teori humor Clarke (2009). Peneliti selanjutnya juga disarankan untuk menggunakan teori umum verbal humor dari Raskin dan Attardo (1994).

\section{DAFTAR RUJUKAN}

Clarke, Alastair. 2009. The Eight Patterns of Humour. Cumbria, UK: Pyrrhic House.

Departemen Pendidikan Nasional. 2008. Kamus Besar Bahasa Indonesia Pusat Bahasa Edisi Keempat. Jakarta: PT Gramedia Pustaka Utama.

Endraswara, Suwardi. 2006. Metodologi Penelitian Sastra, Epistemologi, Model, Teori, dan Aplikasi. Yogyakarta: Pustaka Widyatama.

Grüner, Charles R. 1978 Understanding Laughter. The Working of Wit and Humor. Chicago: Nelson Hall.

Gruner, C. 1997. The game of humor: A comprehensive theory of why we laugh. New Brunswick, NJ: Transaction.

Hobbes, T. 1968. Leviathan. Harmondsworth, England: Penguin. (Original work published 1651)

Jarkasi. 2004. Madihin, Hakikat, Fungsi, Formula. Banjarmasin: Forum Kajian Budaya Banjar Kalimantan Selatan.

Kawi, Djantera; Jarkasi; dan Kusasi, Zakiah Agus. 1994. Sastra Lisan Madihin. Banjarmasin: Proyek Pembinaan Bahasa dan Sastra Indonesia dan Daerah Kalimantan Selatan.

Kirkmann, Arvo. 2006. Contemporary Linguistic Theories of Humour. Folklore 33, p.2758.

Kotthoff, Helga. 2007. Oral Genres of Humor: On The Dialectic of Genre Knowledge and Creative Authoring. Pragmatics, 17 (2): 263-296.

Krippendorff, Klaus. 1980. Analisis Isi, Pengantar Teori dan Metodologi. Terjemahan oleh Farid Wajidi. 1991. Jakarta: Rajawali Pers.

Mulder, M.P. and Nijholt, A. 2002. Humour Research: State of the Art. University of Twente, Center of Telematics and Information Technology, Technical Report CTIT-0234.

Rafiek, M. 2007. Madihin Banjar: Suatu Tinjauan Etimologi dan Struktur Pementasannya di Kalimantan Selatan. Ansos, Jurnal Analisis Sosial, 5 (1): 69-80.

Rafiek, M. 2012. Humor dalam Pantun Madihin Jhon Tralala dan Hendra, Anaknya. Banjarmasin: Program Studi Magister Pendidikan Bahasa dan Sastra Indonesia, Program Pascasarjana Universitas Lambung Mangkurat.

Rafiek, M. 2012b. Pantun Madihin: Kajian Ciri, Struktur Pementasan, Kreativiti Pemadihinan, Pembangunan dan Pembinaannya di Kalimantan Selatan. Jurnal Pendidikan Bahasa Melayu, 2 (2): 104-114.

Rafiek, M. 2013. Pemasyarakatan Bahasa Indonesia melalui Madihin Banjar Jhon Tralala dan Hendra sebagai Upaya Mempererat Persatuan Bangsa Indonesia. Jurnal Bahasa dan Sastra, 3 (2): 184-195.

Rafiek, M. 2014. Bahasa Humor dalam Syair atau Pantun Madihin. Prosiding Seminar Pendidikan Pengajaran dan Pembelajaran, Strategi Pengajaran dan Pembelajaran, 3 Desember 2014, (Hal. 326-335). Bangi Selangor: Dewan Budiman, Fakulti Pendidikan, Universiti Kebangsaan Malaysia. 
Rahmanadji, Didiek. 2007. Sejarah, Teori, Jenis, dan Fungsi Humor. Bahasa dan Seni, 35 (2): 213-221.

Raskin, Victor 1985. Semantic Mechanisms of Humor. Dordrecht \& Boston \& Lancaster: D. Reidel Publishing Company.

Raskin, Victor \& Attardo, Salvatore 1994. Non-literalness and non-bona-fide in language. Pragmatics and Cognition, 2 (1), pp. 31-69.

Ratna, Nyoman Kutha. 2015. Teori, Metode, dan Teknik Penelitian Sastra dari Strukturalisme hingga Postrukturalisme Perspektif Wacana Naratif. Yogyakarta: Pustaka Pelajar.

Seman, Syamsiar. 2010. Kesenian Tradisional Banjar Lamut, Madihin, dan Pantun. Banjarmasin: Lembaga Pengkajian dan Pelestarian Budaya Banjar Kalimantan Selatan.

Sukerti, Gusti Nyoman Ayu dan Basthomi, Yazid. 2016. LAUGHTER AFTER TEARS: SITTING FOR AMERICAN HUMORS IN INDONESIAN SOFAS (Subtitling Humors of a Tv Serial Friends). Bahasa dan Seni, 44 (2): 188-206.

Thaha, M dan Sanderta, Bakhtiar. 2000. Pantun, Madihin, Lamut. Banjarmasin: Dinas Pendidikan dan Kebudayaan TK. I Kalimantan Selatan dan Dewan Kesenian Kalimantan Selatan.

Veatch, Thomas C. 1998. A Theory of Humor. Humor, 11-2: 161-215. 